\title{
X-ray Diffraction and Spectral Investigation of the Consequences of Obtaining Impurities from a Material of a Reactor to Obtain the Titanium Sponge
}

\author{
IVAN CHERVONY] ${ }^{1}$, DMYTRO LISTOPAD ${ }^{1}$, DIMITRII SHAKHNIN² , VICTOR MALYSHEV ${ }^{2}$, CRISTINA DONATH ${ }^{3}$, \\ ELENA IONELA NEACSU ${ }^{3 *}$, VIRGIL CONSTANTIN³, ANA-MARIA POPESCU ${ }^{3 *}$ \\ ${ }^{1}$ Department of Metallurgy of Non-Ferrous Metals, Zaporizhzhia State Engineering Academy, Soborny Ave., 226, Zaporizhzhia \\ Ukraine \\ ${ }^{2}$ Institute for Engineering \& Technology, University Ukraine, Kyiev, Ukraine \\ 3 Illie Murgulescu Institute of Physical Chemistry of the Romanian Academy, Laboratory of Electrochemistry and Corrosion, 202 \\ Splaiul Independentei, 060021, Bucharest, Romania \\ Impurity level in a titanium sponge is essential for a pure titanium production. Using X-ray diffraction and \\ spectral microanalysis the qualitative character of element distribution from a deep surface into different \\ samples from the reactor was studied. Studying microphotographs of micro-sections of samples it was also \\ identified the definition processes proceeding with a material of a reactor during titanium operation.
}

Key words: titanium sponge, impurities, XRD, microphotography, stainless steel detruction

One of the primary goals in production of titanium metal is the minimum impurity level, this over time, the obtaining of titanium has generated multiple studies [1-5].

Titanium metal, which has excellent properties such as low weight, high strength, and high corrosion resistance, is commercially produced by the magnesiothermic reduction of titanium tetrachloride $\left(\mathrm{TiCl}_{4}\right)$; this is known as the Kroll process $[6,7]$. The current titanium production process has several advantages, including the production of high-purity titanium with low oxygen content obtainable. This processe produces titanium in the form of a highly porous material called "sponge", with the $\mathrm{MgCl}_{2}$ entrapped in the pores. The sponge is, jackharmmered out, crushed, and the metal and salts are separated by either a dilute acid leach or by high-temperature vacuum distillation. However the Kroll process is unsuitable for the development of a continuous reduction process because generated titanium deposits which firmly adhere to the inner stainless steel wall of the reaction container (retort). At present, all commercial titanium production synthesis are carried outby a labor-intensive batch-type process. The basic sources of impurities in a titanium sponge occur in four ways [8]: by diffusing directly in the sponge formed on walls reactor; by dissolution in magnesium reagent; through a gas phase, by interaction with titanium tetrachloride; and as a result of salt high-temperature corrosion due to such substances as $\mathrm{MgCl}_{2}$ and $\mathrm{MgCl}$. The content of undesirable impurities in titanium sponge in the course of production essentially affects mechanical characteristics of the titanium melted from a sponge. During carrying out of process athigh temperature loadings (to $1050^{\circ} \mathrm{N}$ [9]) the aggressive influence of titanium chlorides and magnesium reaction inside (and also a melt of magnesium) as well as the oxidation by atmospheric oxygen. The sponge which is near to walls and at the bottom of the reactor contains impurities much more than a sponge which is in the central zones [10]. A part of impurities in the form of chlorides reacts with magnesium chloride and merges together out from the reactor. Magnesium chloride and other impurities entering or formed during the process (nitrogen, carbon, oxygen) partially leave the reaction zone. Usual serviceable life of a reactor is 36-38 cycles [11]. One of the reasons for design an operating reactor is the deformation of the retort which is made by structural stainless steels. [12]

The purposes of this work are: studying of qualitative character of element distribution from a deep surface into the sample at constant composition as well as the definition of processes reactor wall during operation.

\section{Experimental part}

Four metal samples cut from the retort as presented in Fig.1, have been selected for analysis. For structure revealing, samples were exposed to thermal pickling. Xray diffraction and quantitative spectral microanalysis (XSMA) have been performed using MS-46 equipment presented in figure $2[13,14]$. An X-ray spectral microanalyzer of model MS-46 (manufactured by CAMECA, France) with $1.5 \mu \mathrm{m}$ diameter probe was employed. Combining advanced electron optics, state-of-the-art spectrometer design and dedicated software, the MS-46 performs high accuracy qualitative and quantitative chemical microanalysis.

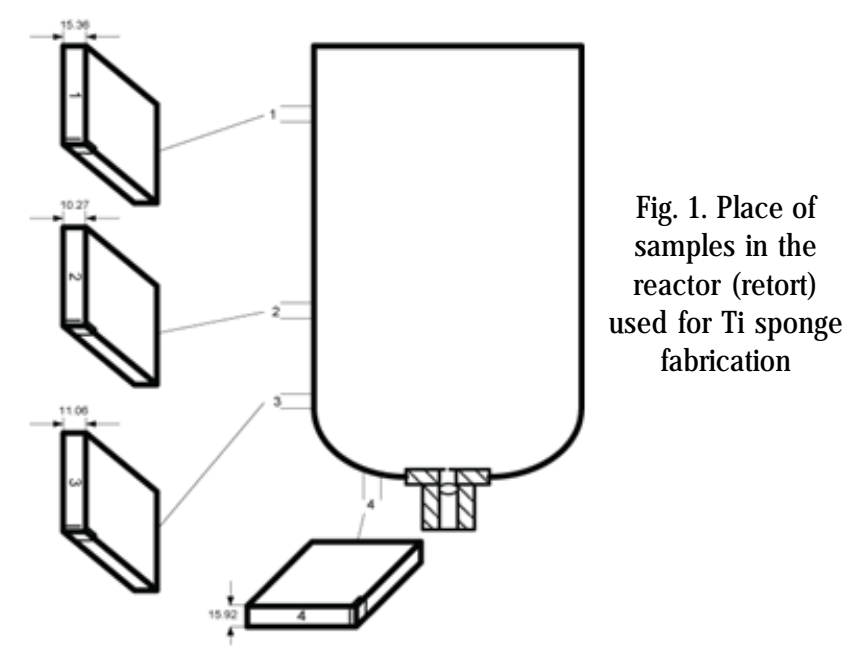

*email: neac_elena@yahoo.com; popescuamj@yahoo.com 


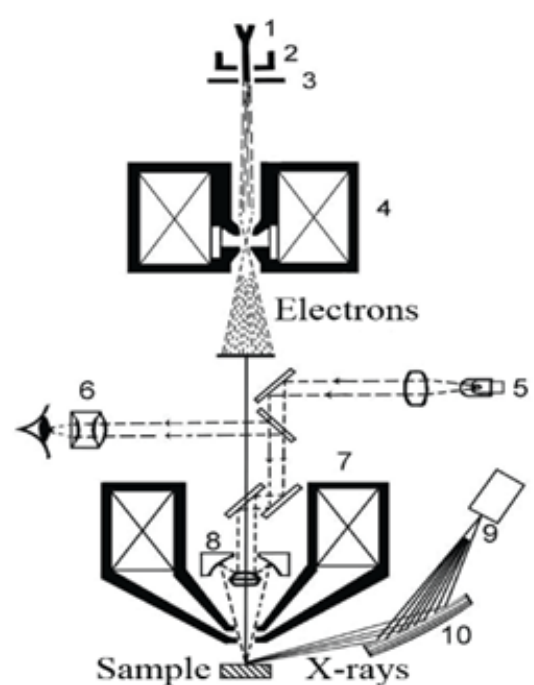

Fig. 2. Scheme of the $X$ ray microevaluation:1an incandescent filament; 2-cylinder Venelta; 3-the anode;4condenser lens; 5 -light source; 6-eyepiece;7objective lens; 8reflective objective; 9 the radiation detector; 10-crystal-analyzer

Intensity of a characteristic $X$-rays for investigated

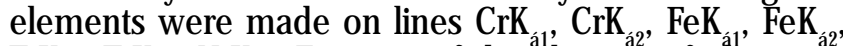
$\mathrm{TiK}_{a_{1}} \mathrm{TiK}_{\text {an }} \mathrm{NiK}_{\text {a1 }}$. Fixation of distribution of elements maintenance was made with a method of linear scanning. We tried to choose sites for scanning so that superfluous phases (local inclusions) do not deform, or deformed in the minimum degree the distribution of elements on the sample.

\section{Results and discussions \\ First sample}

From metallographic pictures we have found out a zone of change of chemical composition (fig. 3-jump of the maintenance of all alloying elements) on depth 400-500 $\mu \mathrm{m}$. On this border there are connections of the titanium which meet as on borders, and inside austenite grains. On borders of austenite grains the diffusion of the titanium from a surface inside and allocation carbon-nitrogen phases on the basis of the titanium are observed. More close to a surface, on more light area the light intermetallids type $\chi$ and $\sigma$-phases $\mathrm{Fe}-\mathrm{Cr}$ are appreciable. For figure 3 and the following figures for the other samples, the $X$-axis indicates the depth from the surface of the sample into the deep of the metal to a depth at which no significant change in composition occurred, i.e. the composition approached the composition of the starting material of the $12 \times 18$ N10T steel.

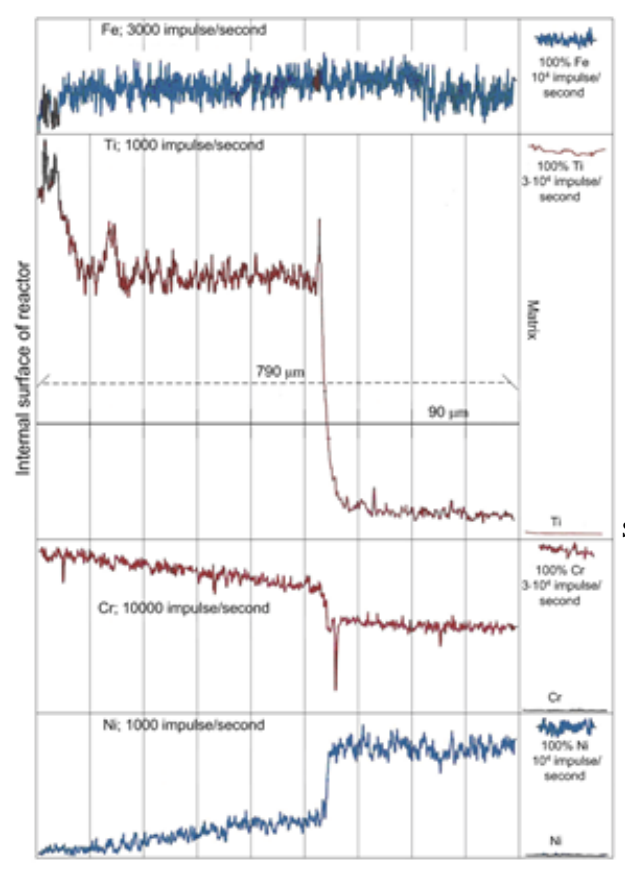

Fig. 3. Graph of qualitative $\mathrm{Fe}, \mathrm{Ti}$,

$\mathrm{Cr}$ and $\mathrm{Ni}$ distribution on section of the first sample, depth up to $790 \mu \mathrm{m}$ into metal
On figure 3 we can see the increase of the maintenance of nickel and falling of the content of chromium from an internal surface of a reactor deep into matrixes. Nickel weakening creates conditions for development in surface layer $\gamma$ - $\alpha$ transformations and formations of sites of ferrite which are promoted by a heat of conducting process of restoration. Simultaneously chromium and titan, possessing larger solubility in $\alpha$-phase, intensively diffuse in the formed ferrite combining thus sites of austenite, located near to interface $\gamma-\alpha$. At cooling in aggregated by chromium and the titanium sites of austenite, a volume fraction precipitating out carbide and carbonitride inclusions decrease. At reheating, there is an intensive growth of austenite grains since barrier influence of a dispersed phase on process of grains migration and absorption by them of smaller drops. The shallow layer of austenite structures with a direction continuous border of partition is formed this border migrates in from an internal retort to an external surface. In process of border advance, deep into the metal braking action of particles of the second phase on process of its migration increases. The further increase in a thickness of bed with coarse-grained structure can occur on the mechanism of dispersion of unstable borders of grains to the subsequent redistributed dislocations formation and migration of incoherent sites of twinning borders with fine grain absorption [15]. Areas of an incipient state of surface degradation-diffusion of the titanium and infringement of integrity of metalintercrystalline destruction (fig. 4) are found out. Their occurrence it is possible to be explained as follows: the titanium, crystallizing in the course of restoration on reactor walls, diffuses deep into metal, embedded simultaneously with the elements which are a part of a material of a reactor.

During diffusive processes there is an allocation of the titanium in places of destruction of metal. At the subsequent T-change, due to different temperatureexpansion coefficients of steel and the titan, there is a further destruction of metal. Formation of fusible eutectics Ti-Fe-Me is thus possible, having $1085^{\circ} \mathrm{N}$ fusion temperature [16].

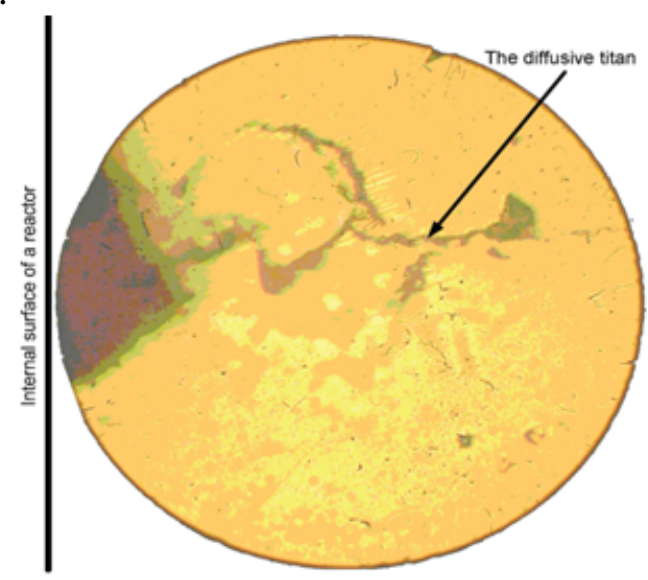

Fig. 4. Microphotograph of a microsection of first sample, a place of destruction of metal at intercrystalline corrosion (along break lines the titanium has precipitated out)

\section{Second sample}

Atstudying of the second sample from a surface to depth $2250 \mu \mathrm{m}$ some changes in composition of metal are found out (fig. 5). On depth to $1925 \mu \mathrm{m}$ there is the structurallychanged zone revealed by thermal pickling found. This zone is spotted by finely divided connections of the titanium (on distribution graphs high peaks are visible). In areas of associates of connection, the maintenance of the titanium comes nearer to background that may be explained by redistribution of the titan.

http://www.revistadechimie.ro 
It is possible to explain distribution of the maintenance of the titanium to the fake that in the course of restoration and separation the titanium atoms diffuse in a steel, followup sating its surface up to $2 \%$ and, then makes through into bed with coarse-grained austenite structure on depth to $4 \mathrm{~mm}$ and more (most brightly it is visible on depth to 2 $\mathrm{mm})$.

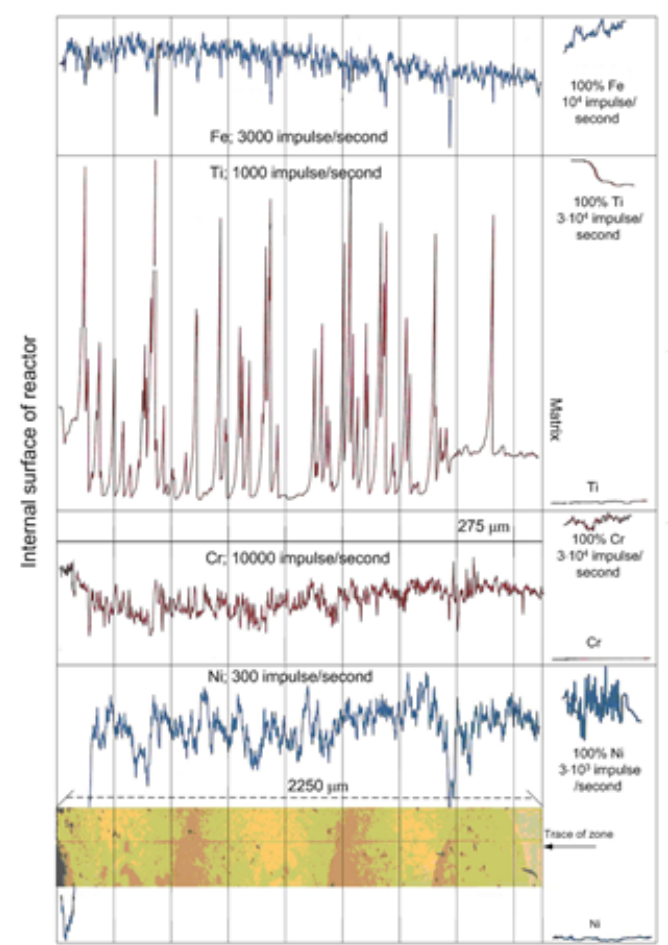

Fig. 5. Graph of qualitative distribution $\mathrm{Fe}, \mathrm{Ti}, \mathrm{Cr}$ and $\mathrm{Ni}$ on section of the second sample deep into metal to $2250 \mu \mathrm{m}$

At the subsequent T-changes, as a result of ageing in coarse-grained bed of metal, the additional quantity precipitating out of carbonitride inclusions which cause steel hardening, despite significant growth of austenite grains is observed.

As the content of the titanium in austenite cannotexceed $0.1-0.2 \%$, it means that all titanium has passed in carbonitride which have precipitated out on borders of grains (just in those places where intercrystalline corrosion begins), but there are connections of the titanium and in austenite grains. On figure 5 these inclusions can be defined as high peaks on a drawing of distribution of the titanium. They have precipitated out with crystals of carbonitrates in the form of a separate phase which registers XSMA as areas with very high content of the titan.

While in service, type 12018100 stainless steel became capable to additional hardening [16] for the allocation of carbonitride phases at preservation of high plasticity. Also the formation multichromic ferrites to a steel (high peak of the content of chromium at the surface) is observed.

At the very beginning of probe movement there was more light zone (as well as in the first sample) which was displayed on spectrums $\mathrm{Cr}$ and $\mathrm{Ni}$. The chrome maintenance sharply increases (initial peak on a drawing is strongly truncated), and the nickel maintenance sharply falls practically to background values. At the further advance, the probe has got to a zone visually expressed with more dark color in which there were no jumps of the maintenance of chromium.

Sites of destruction in metal (fig. 6) are revealed outwardly. The surface looks as if metal has undergone to flash-off suggesting that the developed porosity whitnesses-owing to primary fusion and metal after contraction take place. Such changes are connected with a lack of austenite steels alloyed by the nickel, forming fusible eutectic Ti-Fe-Ni, with melting point $960-1000^{\circ} \mathrm{C}$. It result is a gradual foundering of walls of a reactor. Probably, such processes begin with local areas in which not only metal was melted off; in our case it has still undergone to chemical corrosion by chloric connections.

On figure 7 the microbreak in which there are chromium and titanium chlorides is visible.

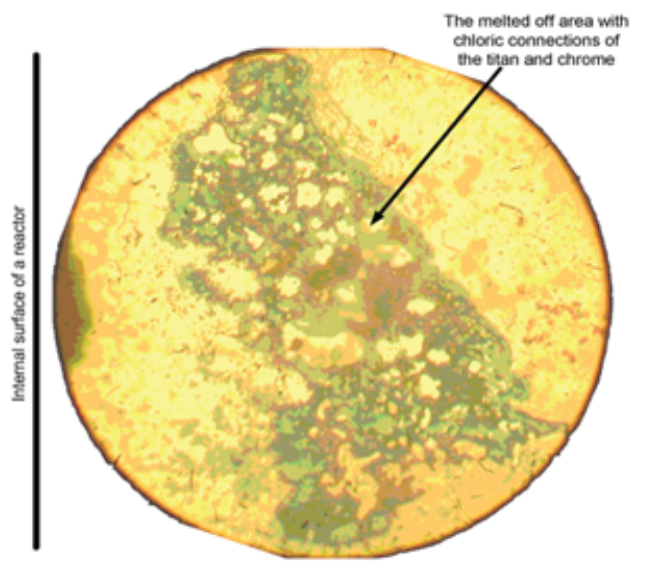

Fig. 6. Microphotographs of a microsection of the second sample.

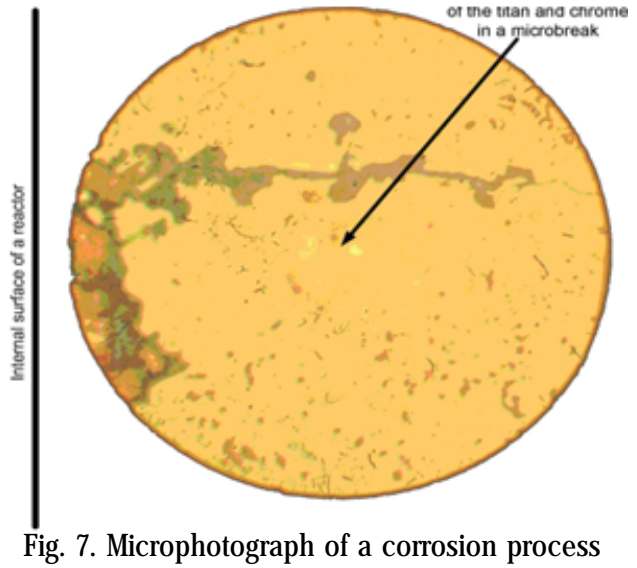

\section{Third sample}

At metallurgical survey of the third sample (fig. 8) some light and dark sites are found out visually. In more dark area needle clusters with light border are visually found out. In area with needlelike structure the small maintenance of the precipitated out large phases on the basis of the titanium (are visible as black points) is noted. At bigger increase in area with needlelike structure the phases on the basis of the titanium in the form of small formations on borders of needlelike structures are noted. In light area without clusters the small formations are not present; there are only large phases on the basis of the precipitated titanium.

In the third sample there is an allocation carbonitrates phases similar to the second sample, however, to a lesser degree. On all investigated depth of 3rd sample the jumps of composition are not registered. This fact is probably connected with that the maintenance of aggressive substances is not enough in a zone from which was the investigated sample is taken or that the bed of metal with the changed chemical composition has been abrasively destroyed (erased) by the block of a settling sponge. 


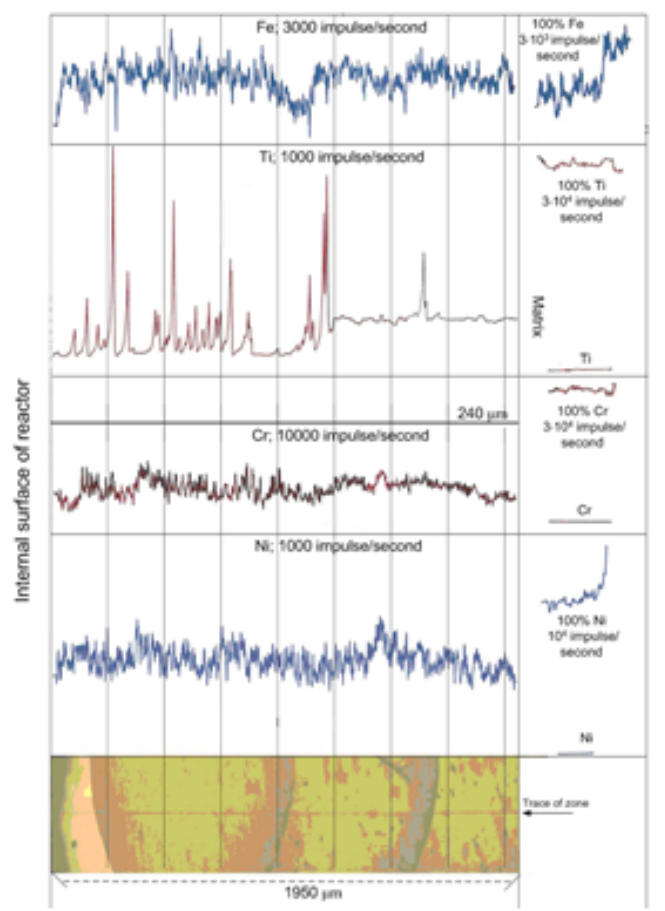

Fig. 8. Graph of qualitative distribution of $\mathrm{Fe}, \mathrm{Ti}, \mathrm{Cr}$ and $\mathrm{Ni}$ on section of the third sample, deep into metal to $1950 \mu \mathrm{m}$

\section{Fourth sample}

At metallurgical survey of the fourth sample (fig. 9 and 10) accurately designated borders between bed of metal with the changed composition on an internal surface of a reactor are visible. Area at thickness in some micron is more displayed as sharp increase the titanium maintenance and falling of chromium maintenance. Metal located on depth behind it-visually has more light color, in it very light sites, presumably identified as intermetalids type $\chi$ and $\sigma$-phases Fe-Cr. These characteristic areas are observed in all samples and probably related to the characteristics of a stainless steel structure.

The luminous area, compared to the darkest, possesses the change of composition, namely the increase of the nickel from a metal surface and the decrease of the chromium while the titanium practically does not vary. Increase of the maintenance of chromium and the titan,

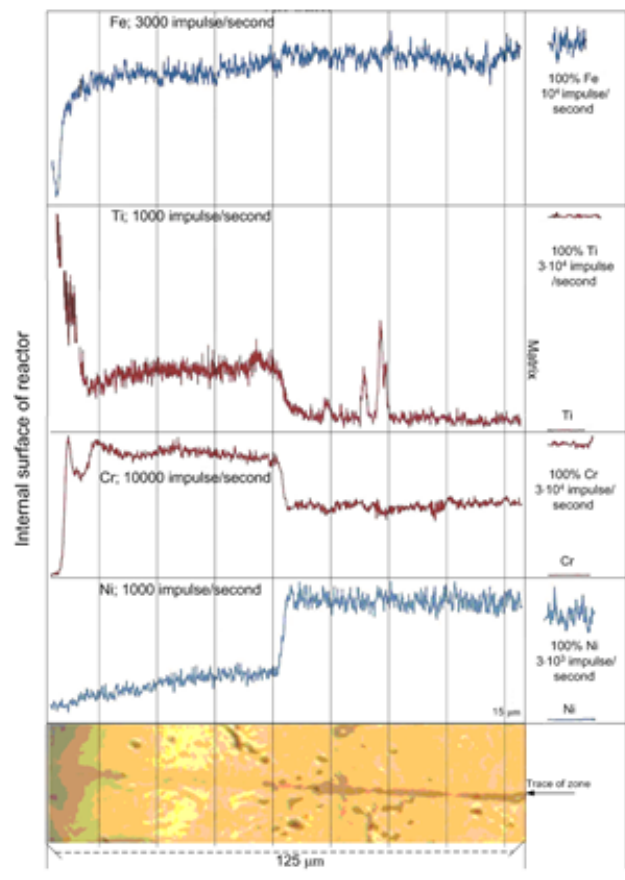

REV.CHIM. (Bucharest) $\bullet 70 \diamond$ No. 7 2019

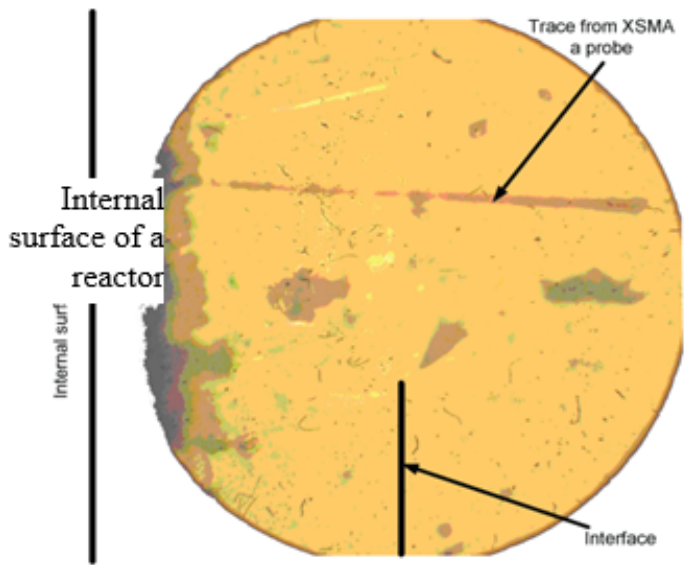

Fig. 10. Microphotograph of a trace from XSMA probe, in the middle of a photo there is a border

and simultaneous weakening of nickel on an internal surface of a retort result to formation of a shallow layer of the steel containing to $80 \%$ of a-phase which is separated from other metal by continuous interface. Structures formed on an internal surface the metal bed, corresponds to ferriteaustenite to steel with high content of chromium and low content of nickel; these define stability of a material of a retort to influence of resultants of reaction of restoration. Formed near-surface steel layer is rather resistant against influence of $\mathrm{TiCl}$, and the durability of a retort is limited by degree of stability of steel to corrosive attack of a melt of magnesium and $\mathrm{MgCl}_{\text {. }}$ On border of light and dark area of a spectrum composition the jump is noted; this means that the nickel contentsharply increases to level in a matrix, the chromium and titanium content falls to the content in a matrix. Structural changes in metal are similar to transformations described for the second and third samples. In figure 10 in the left part around is an internal surface of the retort, while darker zone represents the raised maintenance of the titanium.

\section{Conclusions}

Impuritylevel in a titanium sponge depends on corrosion and thermo-mechanical properties of a material of reactor wall during restoration of $\mathrm{TiCl}_{4}$ and technological parameters of carrying out of process. During performed research it is defined, that the greatest quantity of impurities in titanium sponge passes from mid-range of a material of a reactor for the expense of chemical influence of reactionary weight, due to bilateral diffusion of elements of the material of reactor wall and processes of crystalline modification and change of composition of a steel.

Acknowledgements: This work was developed under the RomanianUkrainean collaboration under the coordination of the Romanian Academy in the framework of the research project, Ilie Murgulescu Institute of Physical Chemistry, nr.3-Electrode processes project, new electrical and corrosion system material, the theme nr.3.10Ionicliquids: Properties and Electrochemical Applications. Authors equally contributed to this work.

\section{References}

1. MALYSHEV, V.V., SHAKHNIN, D., Mater. Sci., 50, no.1, 2014, p. 80.

2. MALYSHEV, V.V., GAB, A., BURSKOVA, D.M., ASTRELIN, A., POPESCU,

A.M., CONSTANTIN, V., Rev. Roum. Chim., 54, no.1, 2009, p. 5.

3. SHAPOVAL, V.I., ZARUTSKY, I.V., MALYSHEV, V., USKOVA, N.N., Chem. Rev., 68, no.11, 1999, p. 925.

4. SHAPOVAL, V.I., ZARUTSKY, I.V., MALYSHEV, V.V., Elektrokhimiya, 34, no.10, 1998, p. 1107.

5. POPESCU, A.M., OLTEANU, M., ZUCA, S., Rev. Chim. (Bucharest), 44, no.1, 1993, p. 39.

http://www.revistadechimie.ro 
6. KROLL, W., Tr. Electrochem. Soc., 78, 1940, p. 35.

7. TAKEDA, O., OKABE, T.H., Mater. Trans., 47, no.4, 2006, p. 1145.

8. RATNIKOV, V.I., PROKUDINA, V.K., BELIKOVA, V.K., SACHKOVA, N.V.,

Russ. J. Non-ferrous Metals, 51, 2010, p. 352.

9. GARMATA, V.A., GULYANITSKII, B.S., KRAMNIK, V.Yu., Metallurgiya, 1967, p. 643

10. TELIN, V.V., TESLEVICH, S.M., DAVIDOV, S.A., SHVARTSMAN, L.J ., PETRUNKO, A.N., JATSENKO, I.P., NARUSHIV, G.A., Proceed. Intern. Conf. Ti-2005 in CSI, Kiev, Ukraine, 2005.

11. TARSOV, A.V., Titanium metallurgy, ICC Akademkniga, III, no.85, 2003, p. 328.
12. POPESCU, A.M., CONSTANTIN, V., Rev. Roum. Chim., 43, 1998, p. 793.

13. MALYSHEV, V.V., SHAKHNIN, D., B. Mater. Sci., 50, no.1, 2014, p. 80. 14. MOLTOVSKA, L., SHAKHNIN, D.,USKOVA, N., NIKULINA, G., CHEREDNIK, V., STUKOVA, S., MALYSHEV, V.V., .J . Chem. Chem. Eng., 1, 2016, p. 7.

15. MASLEKOV, B., MASLEKOVA, E.A., Metallurgy, 1, 1991, p. 382.

16. EREMENKO, V.I., The Titanium and its Alloys, Publishing House of the Acad. Sci., Kiev-USSR (in Russian), 1955, p. 400.

Manuscript received: 28.06 .2018 